\title{
INFLUÊNCIA DE DIFERENTES TURNOS DE REGA E DOSES DE HIDROABSORVENTE NO DESENVOLVIMENTO INICIAL DA CULTURA DO CAFÉ CONILLON (COFFEA CANEPHORA PIERRE)
}

\author{
INFLUENCE OF DIFFERENT IRRIGATION FREQUENCIES \\ AND HYDROABSORBENT DOSES ON THE INITIAL DEVELOPMENT \\ OF CONILLON COFFEE (COFFEA CANEPHORA PIERRE)
}

\author{
João Henrique Zonta ${ }^{1}$; Heder Braun; Edvaldo Fialho dos Reis; \\ Danilo Paulucio; João Batista Zonta
}

\begin{abstract}
RESUMO
Para a obtenção de bons resultados com uso da irrigação no cafeeiro, esta deve ser manejada de forma adequada, disponibilizando água em quantidade suficiente para o desenvolvimento da cultura. Assim, visando melhorar a eficiência do uso da água, polímeros hidroabsorventes têm sido utilizados com o intuito de minimizar a irregular disponibilidade de água para a cultura. Nesse sentido, objetivou-se neste trabalho, avaliar diferentes turnos de rega e doses de hidroabsorvente na fase inicial de desenvolvimento da lavoura de cafeeiro conillon (Coffea canephora Pierre). O experimento foi conduzido em casa de vegetação, localizada no município de Alegre-ES, utilizando a espécie Coffea canephora Pierre, variedade Conillon. O plantio foi realizado em baldes com volume de 10 litros, preenchidos com um Argissolo Vermelho-armarelo distrófico. Os tratamentos consistiram em 4 doses de hidroabsorvente, nas concentrações de: 0; 3,0; 6,0 e 9,0 gramas por balde, e quatro diferentes turnos de rega: 7, 14, 21 e 28 dias, num esquema fatorial $4 \times 4$, com 4 repetições, num delineamento inteiramente casualizado. Foram avaliados, 150 dias após o transplantio das mudas para os baldes, os seguintes parâmetros agronômicos: altura das mudas, diâmetro do caule, massa fresca e seca da parte aérea, massa fresca e seca das raízes e área foliar. O turno de rega de 7 dias e a dose de hidroabsorvente de 9 gramas proporcionou a melhor condição para o desenvolvimento inicial da cultura do café conillon para a condição em estudo.
\end{abstract}

Palavras-chave: Coffea canephora Pierre, irrigação, desenvolvimento.

\begin{abstract}
Adequate irrigation management to supply water sufficient to meet crop needs will guarantee good results in coffee irrigation. Hydroabsorbent polymers improve water use efficiency by reducing irregular availability of water for crops. In this context, the objective of this work was to evaluate the effect of different irrigation frequencies and hydroabsorbent doses on the initial stage of development of conillon coffee (Coffea canephora Pierre). The experiment was conducted in greenhouse, in the Municipal District of Alegre - ES, using the species Coffea canephora Pierre, variety Conillon. Planting was carried out in 10-L containers filled with Dystrophic Red-Yellow Argisol. The treatments consisted of 4 hydroabsorbent doses (0, 3, 6 and $9 \mathrm{~g}$ per container) and four different irrigation frequencies (7, 14, 21 and 28 days) in a complete randomized $4 x 4$ factorial design with 4 repetitions. The following agronomic parameters were evaluated 150 days after seedling transplanting to containers: seedling height, stem diameter, fresh mass of aerial part, dry mass of aerial part, root fresh mass, root dry mass and leaf area. Irrigation at 7 day intervals and hydroabsorbent at the dose of 9 grams gave the best initial development of conillon coffee under the tested conditions.
\end{abstract}

Key words: Coffea canephora Pierre, irrigation, development.

1 Universidade Federal de Viçosa, Dep. de Eng. Agrícola, joaozonta@hotmail.com

Fecha de Recepción: 12 Septiembre 2007

Fecha de Aceptación: 07 Enero 2008 


\section{INTRODUÇÃO}

A importância do café na economia mundial data do início do século XIX. A partir desse século, ele esteve freqüentemente nas pautas de exportação/importação de um grande número de países que o teve como principal fonte de divisas (Caixeta, 2000).

Dentre os estados brasileiros produtores de café, o Espírito Santo se destaca como o maior produtor de café conillon (Coffea canephora Pierre), com $80 \%$ da produção nacional. No ano de 2006, o estado teve produção de 6.881 .000 sacas de 60 $\mathrm{kg}$, com destaque para os municípios de Jaguaré, Sooretama, Colatina, Rio Bananal, São Gabriel da Palha (CETCAF, 2007).

O cafeeiro, como as demais culturas em geral, necessita de água facilmente disponível no solo em sua fase vegetativa e reprodutiva para se ter um desenvolvimento e produção satisfatória (Camargo, 1989). Como sabemos, a deficiência de água geralmente é o fator mais limitante para se obter uma boa produtividade da cultura. Assim, o uso da técnica de irrigação na cultura do café cresceu acentuadamente em diversas regiões brasileiras, conforme indicam levantamentos preliminares, que mostram que a área irrigada alcança aproximadamente 200 mil hectares, o que representa $10 \%$ da área cultivada com café e $8,7 \%$ da área irrigada no Brasil (Mantovani, 2000).

A cafeicultura irrigada é uma atividade agrícola de muito prestígio, em razão, principalmente, de sua rentabilidade. Muitas vantagens têm sido atribuídas à utilização da irrigação na produção de café, tais como a criação de um ambiente mais favorável à produção e ao desenvolvimento do cafeeiro. Como a utilização da irrigação em escala comercial na cafeicultura é um fato recente, é necessário pesquisar, analisar e reavaliar várias técnicas utilizadas nos sistemas de produção que fazem uso dessa prática (Mendonça, 2001).

Segundo Silva et al. (1998), os benefícios da irrigação para uma determinada cultura só podem ser alcançados em toda a sua plenitude quando o sistema de irrigação for utilizado com critérios de manejo que resultem em aplicações de água em quantidades compatíveis com as necessidades de consumo da cultura.

Visando melhorar a eficiência do uso da água na irrigação, polímeros hidroabsorventes têm sido utilizados com o intuito de minimizar a irregular disponibilidade de água para a cultura. Estes polímeros são arranjos de moléculas orgânicas que, ao serem hidratados, transformam-se em gel, absorvendo cerca de cem vezes ou mais seu peso em água (Fonteno \& Bilderback, 1993). Segundo Silva e Toscani (2000), os polímeros hidroabsorventes podem atuar como uma alternativa para situações em que não há disponibilidade de água no solo, tais como estresse hídrico, períodos longos de estiagem, etc.

Segundo Oliveira et al. (2004), à medida que se aumenta a concentração do polímero nos solos, ocorre uma maior retenção de água, principalmente nos potenciais matriciais mais elevados. Ainda, segundo os mesmos autores, o uso do polímero hidroabsorvente contribuiu para aumentar a retenção de água nos solos de texturas franco-argiloarenosa e argilosa, até o potencial matricial de -1,0 MPa.

A maior parte das pesquisas realizadas mostrouse favorável ao emprego de polímeros nos solos agrícolas, apresentando como principal fator de convergência a melhor utilização da água (Volkmar \& Chang, 1995).

Azevedo (2000) destaca que as raízes das plantas crescem por dentro dos grânulos do polímero hidratado, com maior superfície de contato entre as raízes, água e nutrientes. $\mathrm{O}$ autor observou efeitos satisfatórios do produto sobre mudas de café, aumentando sua altura, massa seca da parte aérea e área foliar.

O aumento da absorção e retenção da água pelo hidroabsorvente tornará a água mais facilmente disponível para as plantas, possibilitando um melhor desenvolvimento inicial destas.

Diante desta situação, o presente trabalho teve como objetivo avaliar diferentes turnos de rega e doses de hidroabsorvente na fase inicial de desenvolvimento da lavoura de café conillon (Coffea canephora Pierre).

\section{MATERIAIS E MÉTODOS}

O experimento foi conduzido em casa de vegetação, localizada no laboratório de Hidráulica, do Centro de Ciências Agrárias da Universidade Federal do Espírito Santo, município de AlegreES, latitude $20^{\circ} 45^{\prime} \mathrm{Sul}$, longitude $41^{\circ} 48^{\prime}$ ' Oeste e altitude de $247 \mathrm{~m}$.

Foi utilizada a espécie Coffea canephora Pierre, variedade Conillon, cujas mudas clonais foram 
produzidas em sacolas plásticas, com dimensões de $20 \mathrm{~cm}$ de altura por $11 \mathrm{~cm}$ de diâmetro, sendo posteriormente transplantadas para baldes com volume de 10 litros.

Para preenchimento dos baldes, foi utilizado um Argissolo Vermelho-armarelo distrófico, previamente destorroado, passado em peneira de $4 \mathrm{~mm}$ e homogeneizado. As características físico-químicas deste solo são apresentadas nas Tabelas 1 e 2.

As correções de acidez do solo e adubação de plantio foram feitas segundo recomendações técnicas para a cultura do cafeeiro no Espírito Santo (Dadalto, 2001). Neste solo, adicionou-se 4 doses de hidroabsorvente, nas concentrações de $0 ; 3,0 ; 6,0$ e 9,0 gramas por balde, distribuindo-o uniformemente em todo solo no momento de enchimento dos baldes.

Afim de garantir o pegamento das mudas no transplantio, foram realizadas irrigações por um período de 10 dias, em todas as parcelas. Após esse período, foram realizadas irrigações em quatro diferentes turnos de rega, sendo 7, 14, 21 e 28 dias. A lâmina de água necessária na irrigação foi calculada pela diferença de peso do balde entre o dia da reposição e o início do experimento, quando todas as parcelas foram pesadas, estando o solo na capacidade de campo. A quantidade de água necessária foi aplicada com uso de proveta graduada.

$\mathrm{O}$ experimento foi instalado em esquema fatorial, 4 x 4 , sendo 4 níveis do hidroabsorvente $(0$; 3; 6 e 9 gramas por recipiente) e 4 níveis de turnos de rega $(7,14,21$ e 28 dias), num delineamento inteiramente casualizado, com 3 repetições.
Aos 150 dias após o transplantio das mudas para os baldes, foram avaliados os seguintes parâmetros agronômicos: altura das mudas $(\mathrm{cm})$ : determinada com auxilio de régua graduada; diâmetro do caule $(\mathrm{cm})$ : determinado através de paquímetro; massa fresca da parte aérea $(\mathrm{g})$ : determinada através de pesagem individual de cada planta, com uso de balança analítica com precisão de $0,01 \mathrm{~g}$; massa seca da parte aérea $(\mathrm{g})$ : efetuando-se a secagem em estufa a $70^{\circ} \mathrm{C}$ e pesando-se em balança analítica até atingirem peso constante (AOAC, 1984); massa fresca das raízes (g): determinada através de pesagem individual de cada planta, com uso de balança analítica com precisão de $0,01 \mathrm{~g}$; massa seca das raízes (g): efetuando-se a secagem em estufa a $70^{\circ} \mathrm{C}$ e pesando-se em balança analítica até atingirem peso constante (AOAC, 1984) e; área foliar $\left(\mathrm{cm}^{2}\right)$ : determinada com medidor LI-COR 3100.

Os resultados foram submetidos à análise de variância e ajustados os modelos de superfície de resposta para os diferentes parâmetros agronômicos avaliados, com uso dos softwares SAEG $5.0 \mathrm{e}$ SIGMAPLOT 9.0.

\section{RESULTADOS E DISCUSSÃO}

As equações ajustadas para cada parâmetro com seus respectivos coeficientes de determinação $\left(R^{2}\right)$ são apresentados no tabela 3 .

Para todos os parâmetros estudados os betas foram significativos, mostrando que houve efeito dos tratamentos em todos os parâmetros. Ainda em

Tabela 1

Características químicas do Argissolo Vermelho-armarelo distrófico utilizado na condução do experimento

\begin{tabular}{|c|c|c|c|c|c|c|c|c|c|c|c|}
\hline $\mathbf{p H}$ & $\mathbf{P}$ & $\mathbf{K}$ & $\mathbf{C a}$ & $\mathbf{M g}$ & $\mathbf{N a}$ & $\mathbf{A l}$ & $\mathbf{H}+\mathbf{A l}$ & $\mathbf{S . B .}$ & $\mathbf{C T C}$ & $\mathbf{t}$ & $\mathbf{V}$ \\
\hline & \multicolumn{2}{|c|}{$\mathbf{m g} / \mathbf{d m}^{\mathbf{3}}$} & $\mathbf{c m o l} / \mathbf{c d m}^{\mathbf{3}}$ & $\mathbf{m g} / \mathbf{d m}^{\mathbf{3}}$ & \multicolumn{5}{|c|}{$\mathbf{c m o l} / \mathbf{c d m}^{\mathbf{3}}$} & $\%$ \\
\hline 6,2 & 12,0 & 74,0 & 1,8 & 0,7 & 3,0 & 0,0 & 1,5 & 2,7 & 4,2 & 2,7 & 64,3 \\
\hline
\end{tabular}

Tabela 2

Análise granulométrica do solo utilizado na condução do experimento

\begin{tabular}{|c|c|c|}
\hline Areia $(\mathbf{g} / \mathbf{k g})$ & Argila $(\mathbf{g} / \mathbf{k g})$ & Silte $(\mathrm{g} / \mathrm{kg})$ \\
\hline 651 & 310 & 39 \\
\hline
\end{tabular}


Tabela 3

Equações de ajuste para altura das plantas, diâmetro do caule, massa fresca e seca da parte aérea, massa fresca e seca do sistema radicular e área foliar, em função do turno de rega e dose de hidroabsorvente, com seus respectivos coeficientes de determinação $\left(\mathbf{R}^{2}\right)$

\begin{tabular}{|l|c|c|}
\hline \multicolumn{1}{|c|}{ Parâmetro } & Equação de ajuste & R2 \\
\hline Altura das plantas $(\mathrm{cm})$ & $\hat{Y}=36,265+0,197 \cdot$ Dose $-1,815 \cdot T R+0,039 \cdot T R^{2}$ & 0,82 \\
\hline Diâmetro do caule (cm) & $\hat{Y}=0,607+0,0039 \cdot$ Dose $-0,031 \cdot T R+0,0007 \cdot T R^{2}$ & 0,80 \\
\hline Massa fresca parte aérea (g) & $\hat{Y}=40,738+0,679 \cdot$ Dose $-2,799 \cdot T R+0,06 \cdot T R^{2}$ & 0,86 \\
\hline Massa seca parte aérea (g) & $\hat{Y}=18,026+0,503 \cdot$ Dose $-1,359 \cdot T R+0,028 \cdot T R^{2}$ & 0,75 \\
\hline Massa fresca sist. radicular (g) & $\hat{Y}=25,518+0,403 \cdot$ Dose $-1,70 \cdot T R+0,033 \cdot T R^{2}$ & 0,85 \\
\hline Massa seca sist. radicular (g) & $\hat{Y}=8,830+0,138 \cdot$ Dose $-0,636 \cdot T R+0,013 \cdot T R^{2}$ & 0,78 \\
\hline Área foliar $(\mathrm{cm} 2)$ & $\hat{Y}=873,451+25,721 \cdot$ Dose $-58,187 \cdot T R+1,126 \cdot T R^{2}$ & 0,84 \\
\hline
\end{tabular}

relação as regressões, nota-se que o coeficiente de determinação $\left(\mathrm{R}^{2}\right)$ foi superior a 0,75 , mostrando o bom ajuste dos modelos.

Nas Figuras 1A e 1B são apresentadas às superfícies de respostas referentes à estimativa da altura das plantas e diâmetro do caule, respectivamente. Nota-se que, para ambos os parâmetros avaliados, houve efeito significativo das doses de hidroabsorvente e dos turnos de rega. Para altura de plantas, o valor máximo foi obtido no turno de rega de 7 dias com 9 gramas de hidroabsorvente. $\mathrm{O}$ mesmo tratamento também se mostrou mais eficiente na avaliação do diâmetro do caule. Estes resultados também vêm ao encontro dos obtidos por LIMA et al. (2003), que trabalhando com cafeeiro arábica variedade Rubi, encontraram resultados significativos sobre o parâmetro altura de plantas com o uso de hidroabsorventes.

Os valores de massa fresca e seca da parte aérea são apresentados nas Figuras 2A e 2B, respectivamente. Para ambos os parâmetros avaliados, os melhores resultados foram obtidos no turno de rega de 7 dias com 9 gramas de hidroabsorvente. Ainda nessas figuras, nota-se que, tanto para massa fresca como para massa seca, o efeito do turno de rega foi mais acentuado que o efeito do hidroabsorvente, evidenciando que as plantas de cafeeiro são muito sensíveis ao déficit hídrico. Esses resultados vêm de encontro aos obtidos por Martins et al. (2004), que trabalhando com café conillon sob diferentes turnos de rega encontraram baixo desenvolvimento com turnos de rega de 28 dias.

Os resultados obtidos para massa fresca e seca do sistema radicular encontram-se nas Figuras 3A e 3B. Os resultados mostram que para ambos os parâmetros houve efeito significativo tanto do turno de rega como das doses de hidroabsorvente. Os melhores resultados foram obtidos no turno de rega de 7 dias com 9 gramas de hidroabsorvente. Da mesma maneira que o observado para a massa fresca e seca da parte aérea, o turno de rega apresentou maior efeito para ambos os parâmetros avaliados.

A Figura 4 mostra os resultados de área foliar obtido nos diferentes tratamentos. Seguindo a mesma tendência dos demais parâmetros estudados, o melhor resultado foi obtido no turno de rega de 7 com a dose de 9 gramas de hidroabsorvente. Nota-se também que a área foliar se mostrou mais sensível ao turno de rega do que ao hidroabsorvente.

Quando analisamos o efeito do hidroabsorvente em todos os parâmetros estudados, o efeito significativo deste pode ser atribuído a melhor retenção de água no solo promovida por ele, condição esta observada por Oliveira et al. (2004). Mendonça et al. (1999) e Azevedo (2000) encontraram resposta significativa no uso de hidroabsorventes para altura de planta e massa seca da parte aérea em mudas de cafeeiro, chegando a afirmar que a presença 

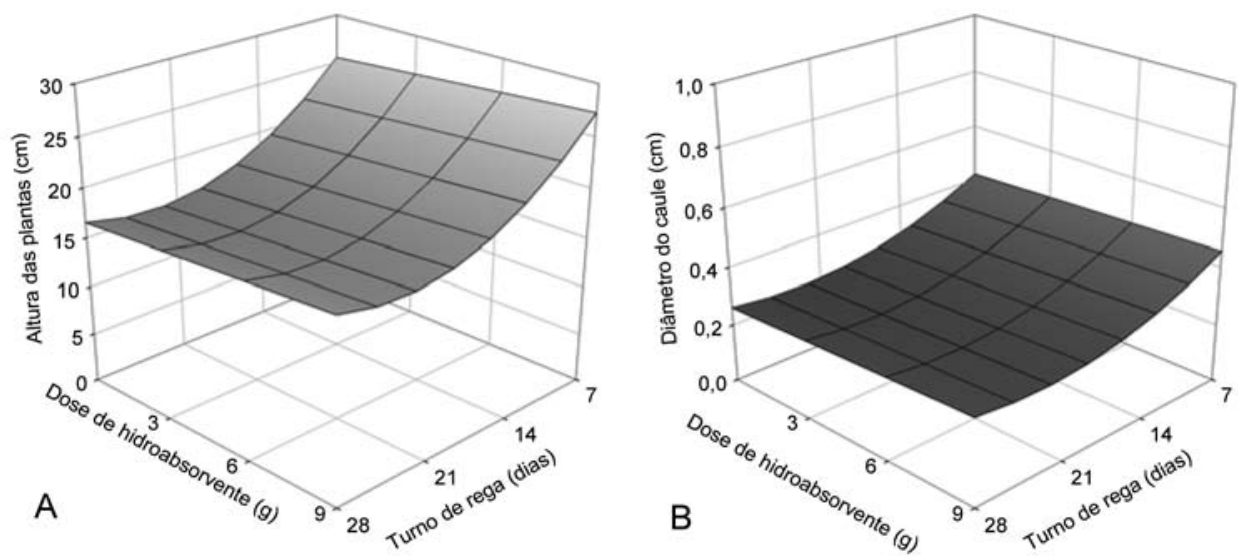

Figura 1. Altura das plantas (cm) (A) e diâmetro do caule (cm) (B) em função das doses de hidroabsorvente e dos turnos de rega.
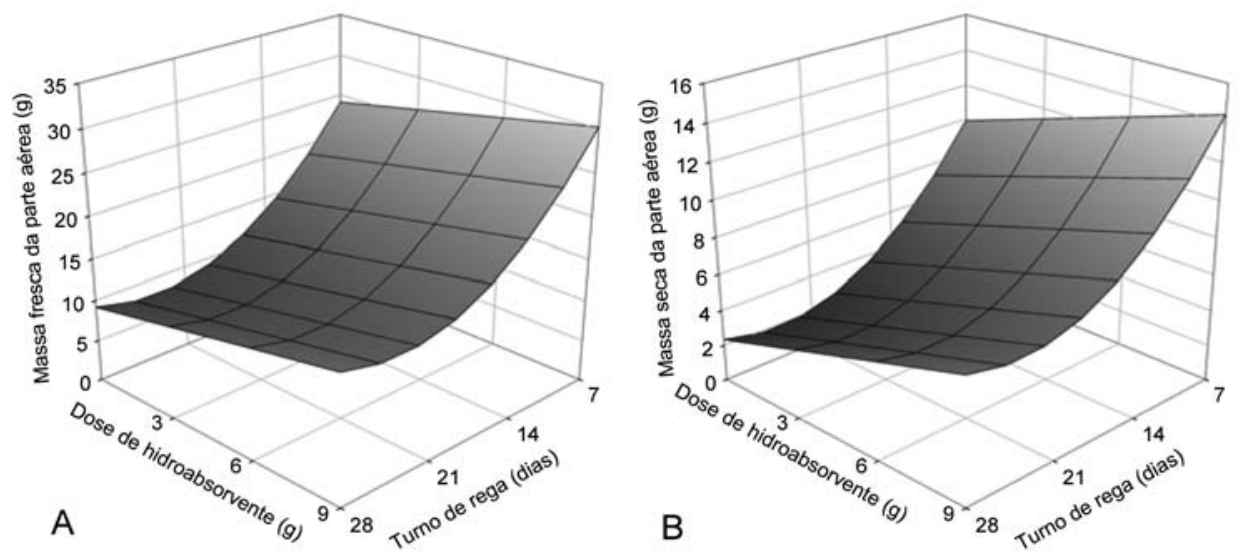

Figura 2. Massa fresca (A) e seca (B) da parte aérea (g) em função das doses de hidroabsorvente e dos turnos de rega.
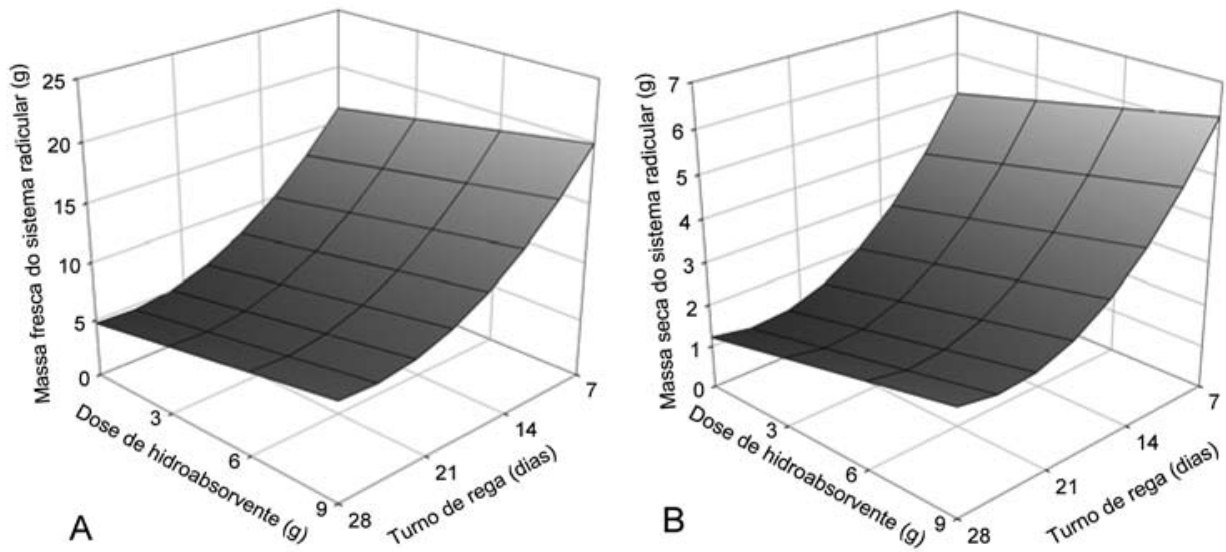

Figura 3. Massa fresca (A) e seca (B) do sistema radicular (g) em função das doses de hidroabsorvente e dos turnos de rega. 


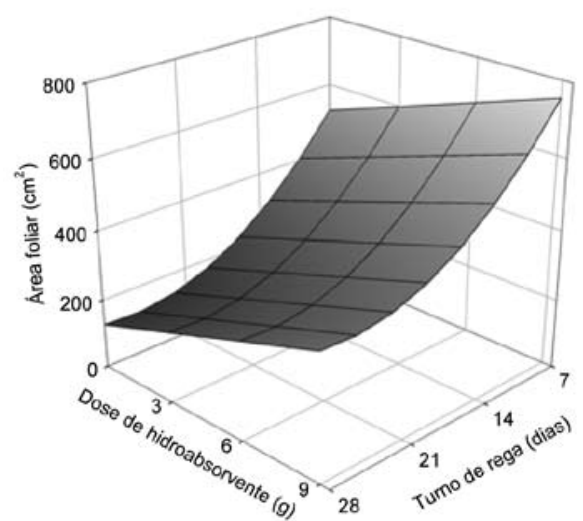

Figura 4. Área foliar $\left(\mathrm{cm}^{2}\right)$ em função das doses de hidroabsorvente e dos turnos de rega.

\section{REFERÊNCIAS}

ASSOCIATION OF OFFICIAL AGRICULTURAL CHEMISTS (Washington, DC). 1984. Official methods of analysis. 9. ed. Washington, DC.: AOAC $832 \mathrm{p}$.

AZEVEDO, T.L.F. 2000. Avaliação da eficiência do polímero agrícola de poliacrilamida no fornecimento de água para o cafeeiro (Coffea arabica). Cv. Tupi. Maringá. Universidade Estadual de Maringá.

CAIXETA, G.Z.T.; ROSADO, P.L.; LIMA, J.E.; GOMES, M.F.M. 2000. Parcelas de participação, qualidade e preço do café no mercado. Belo Horizonte: EPAMIG, 48 p. (Boletim Técnico, 60).

CAMARGO, A.P. DE. 1989. Necessidades hídricas do cafeeiro. In: CURSO PRÁTICO INTERNACIONAL DE AGROMETEOROLOGIA, 3, Campinas: IAC, 1989. $20 \mathrm{p}$.

CETCAF. 2008. Disponível em: <<http://www.cetcaf.com. $\mathrm{br} /$ Links/cafeicultura\%20capixaba.htm $>>$ Acesso em 28/08/2008

DADALTO, G.G.; FULLIN, E.A. 2001. Manual de recomendação de calagem e adubação para o Estado do Espírito Santo-4a aproximação. Vitória, ES: SEEA/INCAPER, 266 p.

FONTENO, W.C. \& BILDERBACK, T.E. 1993. Impact of hydrogel on physical properties of coarse- structured horticultural substrates. J. Am. Soc. Hort. Sci., 118; p. 217-222.

LIMA, L.M.L. DE; TEODORO, R.E.G.; FERNANDES, D.L.; CARVALHO, H.P.; MENDONÇA, F.C.; CARVALHO, J.O.M. 2003. Produção de mudas de café sob diferentes lâminas de irrigação e doses de um polímero hidroabsorvente. Bioscience in Journal, Uberlândia, v. 19, n. 3, p. 27-30.

MANTOVANI, E. C. 2000. A irrigação do cafeeiro. ITEMIrrigação e Tecnologia Moderna, Brasília: Associação Brasileira de Irrigação e Drenagem, n. 48, p. 50-55. deste no substrato permite ampliar os intervalos entre irrigações sem comprometer o crescimento da planta quando esta se encontra em condições de déficit hídrico.

\section{CONCLUSÃO}

O turno de rega de 7 dias e a dose de hidroabsorvente de 9 gramas proporcionou a melhor condição para o desenvolvimento inicial da cultura do cafeeiro para a condição em estudo.

Os turnos de rega de 14, 21 e 28 dias, mesmo com o uso de hidroabsorvente, não proporcionaram um bom desenvolvimento das mudas de cafeeiro.

MARTINS, C.C.; REIS, E. F.; BUSATO, C.; PEZZOPANE, J.E.M. 2004. Desenvolvimento inicial do cafeeiro conilon (coffea canephora pierre) submetido a diferentes turnos de rega e doses de hidroabsorvente. Engenharia na Agricultura, Viçosa, MG, v. 12, n. 3, 222-228.

MENDONÇA, F.C.; SANTOS, C.M.; ZAGO, R.; SANTOS, V.L.M. DO. 1999. Uso do condicionador terracottem na produção de mudas de cafeeiro em tubetes. In: SIMPÓSIO BRASILEIRO DE PESQUISA EM CAFEICULTURA IRRIGADA, 2, 1999, ARAGUARI. Resumos e Palestras... Uberlândia: EDUFU.

MENDONÇA, F. C. 2001. Evolução dos custos e avaliação econômica de sistemas de irrigação usados na cafeicultura. In: SIMPÓSIO BRASILEIRO DE PESQUISA EM CAFEICULTURA IRRIGADA, 3., 2000, Araguari. Resumos e Palestras... Uberlândia: UFU/DEAGRO, v. 1, p. 45-78.

OLIVEIRA, R.A. DE; REZENDE, L.S.; MARTINEZ, M.A.; MIRANDA, G.V. 2004. Influência de um polímero hidroabsorvente sobre a retenção de água no solo. Revista Brasileira de Engenharia Agrícola e Ambiental, v. 8, n. 1, p. 160-163.

SILVA, E.M., AZEVEDO, J.A., GUERRA, A.F., FIGUERÊDO, S. F., ANDRADE, L. M., ANTONINI, J.C.A. 1998. Manejo de irrigação para grandes culturas. In: FARIA, M. A., SILVA, E. L., VILELA, L. A. A., SILVA, A. M. (Eds.) Manejo de irrigação. Poços de Caldas: UFLA/SBEA, p. 239-280.

SILVA, E.T.; TOSCANI, E. 2000. Efeito da adição de polímeros hidroretentor na temperatura de três diferentes substratos em uma casa de vegetação com controle de temperatura e umidade relativa do ar. In: CONGRESSO BRASILEIRO DE ENGENHARIA AGRÍCOLA, 29, 2000. Fortaleza-CE. Anais... Fortaleza: SBEA.

VOLKMAR, K. M. \& CHANG, C. 1995. Influence of hydrophilic gel polymers on water relation and growth and yield of barley and canola. J. Can. Sci. Plant 35: 605-611. 